\title{
Functional aspects of root architecture and mycorrhizal inoculation with respect to nutrient uptake capacity
}

Received: 27 January 2003 / Accepted: 27 May 2003 / Published online: 10 July 2003

(C) Springer-Verlag 2003

\begin{abstract}
The aim of this research was to investigate the effect of arbuscular mycorrhizal (AM) colonisation on root morphology and nitrogen uptake capacity of carob (Ceratonia siliqua L.) under high and low nutrient conditions. The experimental design was a factorial arrangement of presence/absence of mycorrhizal fungus inoculation (Glomus intraradices) and high/low nutrient status. Percent AM colonisation, nitrate and ammonium uptake capacity, and nitrogen and phosphorus contents were determined in 3-month-old seedlings. Grayscale and colour images were used to study root morphology and topology, and to assess the relation between root pigmentation and physiological activities. AM colonisation lead to a higher allocation of biomass to white and yellow parts of the root. Inorganic nitrogen uptake capacity per unit root length and nitrogen content were greatest in $\mathrm{AM}$ colonised plants grown under low nutrient conditions. A better match was found between plant nitrogen content and biomass accumulation, than between plant phosphorus content and biomass accumulation. It is suggested that the increase in nutrient uptake capacity of AM colonised roots is dependent both on changes in root morphology and physiological uptake potential. This study contributes to an understanding of the role of AM fungi and root morphology in plant nutrient uptake and shows that AM colonisation improves the nitrogen nutrition of plants, mainly when growing at low levels of nutrients.
\end{abstract}

C. Cruz $(\bowtie) \cdot$ M. A. Martins-Loução

Centro de Ecologia e Biologia Vegetal (CEBV),

Departamento de Biologia Vegetal,

Faculdade de Ciências da Universidade de Lisboa, Campo Grande, Bloco C-2 Piso 4, 1749-016 Lisboa, Portugal

e-mail: ccruz@fc.ul.pt

Tel.: +351-21-7500000

Fax: +351-21-7500048

J. J. Green · C. A. Watson · F. Wilson

Scottish Agricultural College, Craibstone Estate,

Aberdeen, AB21 9TQ, UK
Keywords Arbuscular mycorrhizae - Carob - Ceratonia siliqua L. - Nitrogen uptake - Root architecture

\section{Introduction}

Most research on the importance of arbuscular mycorrhizal (AM) associations to mineral plant nutrition has focused on their ability to improve plant growth by enhancing phosphorus uptake (Fitter and Hay 2002). Several works have shown that AM fungi can interfere with nitrogen uptake and metabolism (Smith and Read 1997). Nevertheless, there is still controversy concerning their contribution to the nutritional status of the plant (Bouma et al. 2001).

Root architecture, morphology and physiology are key factors in plant productivity and can provide useful information for an appreciation of root nutrient absorbing capacity, especially in environments with low nutrient availability (Lynch 1995). Root system development can be analysed using various mathematical or developmental models (Tisserant et al. 1992). However, these models do not relate functional aspects to root architecture and morphology. To generate hypotheses on root function and on root strategies, topological analyses combined with physiological studies are required.

Many environmental factors such as soil moisture and nutrient concentration have been considered to influence the topological pattern of root systems (Fitter 1986). AM associations have been shown to induce modifications in root architecture and morphogenesis in herbaceous plants as well as in trees (Berta et al. 1990; Schellenbaum et al. 1991; Tisserant et al. 1992), but reports are inconsistent on the kind of modifications imposed by AM association (Barker et al. 1998; Smilauerova and Smilauer 2002). However, very little is known about the way mycorrhiza influence root capacity for nitrogen uptake.

This research follows a series of studies of changes in the morphology and physiology of carob (Ceratonia siliqua L.) roots (Cruz et al. 1995, 1997). Carob is a slowgrowing evergreen, sclerophylous, Mediterranean woody 
plant (Martins-Loução and Brito de Carvalho 1990) well adapted to the marginal nutrient-poor areas of Mediterranean ecosystems.

The aim of this work was to compare the capacity of non-AM roots and AM roots to take up nitrogen, and to assess the effects of AM colonisation on root morphology and architecture, relating measurements of root architecture with root function.

\section{Materials and Methods}

The inoculum

The inoculum was an isolate of Glomus intraradices (Smith and Schenck) which has been in the collection of the del Zaidin Experimental Station, Granada, Spain for over 25 years. Prior to the experiment the inoculum was multiplied by pot culture with maize (Brundrett 1996). The growth medium for the pot cultures was a 1:9 mix of sieved soil $(2 \mathrm{~mm})$ and sand, sterilised by autoclaving. The soil was a silty clay loam topsoil (Panholes series, Rothamsted Estate, Hertfordshire, UK) selected as a surrogate for Mediterranean soil for its high similarity with the Mediterranean soils: high $\mathrm{pH}$ (7.8 in $0.01 \mathrm{M} \mathrm{CaCl}_{2}$ ), fine texture and low organic matter content. A non-AM inoculum was produced by growing maize in the same soil mixture after sterilisation and without propagules. Maize plants were allowed to grow for 6 weeks, after which the shoot was harvested and discarded. The roots were cut into small segments and mixed with the soil, ensuring the same proportion of root material to soil dry weight in mycorrhizal and non-mycorrhizal treatments. The soil with the maize roots was used to grow the carob plants. The nitrogen, phosphorus, potassium and magnesium concentrations of the substrate were $33,200,310$ and $80 \mathrm{mg} \mathrm{kg}^{-1}$ substrate, respectively.

Plant material, growth conditions and experimental design

Seeds of carob ( Ceratonia siliqua L. cv. Mulata), harvested in 1999, were obtained from the Associação Interprofissional para o Desenvolvimento da Produção e Valorização da Alfarroba (Algarve, Portugal). Seed dormancy was broken by placing the seeds in concentrated sulphuric acid $(97 \%)$ for $15 \mathrm{~min}$. The seeds were then washed and imbibed in tap water for $48 \mathrm{~h}$, germinated in an incubator at $25^{\circ} \mathrm{C}$ and transplanted to treatment containers once the radicle had emerged. Treatment containers were cylindrical, $11 \mathrm{~cm}$ in diameter and $50 \mathrm{~cm}$ deep (volume 4.51 ), made from two lengths of plastic guttering joined with silicon sealant. These could be opened, allowing the root systems to be extracted intact on harvesting .

During the 3 months of the experiment, plants were grown in a glasshouse under a photoperiod of $16 \mathrm{~h}$, with photosynthetic active radiation of $350 \mu \mathrm{mol} \mathrm{m} \mathrm{m}^{-2} \mathrm{~s}^{-1}$ at seedling level, mean daily maximum temperature $24^{\circ} \mathrm{C}$ and mean minimum temperature $18^{\circ} \mathrm{C}$. Containers were initially watered to field capacity at the start of the study, and watered with $50 \mathrm{ml}$ water every 3 days. Watering solutions were either deionised water (low nutrients) or Hoagland's solution (high nutrients, solution no.1; Hewitt 1966) which comprises a balanced nutrient solution (nitrogen as $0.611 \mathrm{~g} \mathrm{NO}_{3}^{-}$ $\mathrm{l}^{-1}$, phosphorus as $0.031 \mathrm{~g} \mathrm{PO}_{4}^{3-} 1^{-1}$ and $\left.0.236 \mathrm{~g} \mathrm{~K}^{+} \mathrm{l}^{-1}\right)$ with an extensive micronutrient supplement (Hewitt 1966). In total, each plant (one per pot) received 1.51 deionised water or nutrient solution, and plants from high nutrient-level treatments received a supplement of $300,900,480$ and $340 \mathrm{mg}$ plant $^{-1}$ of phosphorus, nitrogen, potassium and magnesium, respectively.

The experimental design was a factorial arrangement of mycorrhiza inoculation and nutrition. The four treatments were: (1) no inoculation and no additional nutrition (NML); (2) no inoculation and additional nutrition (NMH); (3) mycorrhiza inoc- ulum and no additional nutrition (ML); (4) mycorrhiza inoculum and additional nutrition (MH). There were ten replicates of each treatment but due to root breakage during extraction only four replicates were used for the root morphology analyses. The roots used for morphology analyses were later used for the determination of nutrient concentrations. The remaining six replicates were used for determination of AM colonisation and nutrient uptake.

\section{Growth morphology}

Three-month-old plants were harvested and total fresh weight determined. Plants were then divided into root and shoot and each part weighed again. Samples of five plants per treatment were oven dried at $50^{\circ} \mathrm{C}$, until constant weight, and then weighed again. The root to shoot ratios were then calculated on a dry weight basis. The dry material was used to determine plant nitrogen and phosphorus contents. Nitrogen was determined by carbon/nitrogen elemental analyses, and phosphorus by the molybdophosphate method (Wantanabe and Olsen 1965).

\section{AM colonisation}

For each root sub-sample, three different groups of root segments were prepared according to their colour and root zones : white (apical region), yellow (elongation zones) and brown (nature zone) (Cruz et al. 1995). After collection, roots were stored in 50\% ethanol. Mycorrhiza staining (Correia and Martins-Loução 1997) was initiated by heating the roots in $10 \% \mathrm{KOH}$ for 60 min at $90^{\circ} \mathrm{C}$ and washing them in water. Roots were bleached in alkaline $\mathrm{H}_{2} \mathrm{O}_{2}$ for 2 days, after which they were rinsed in water and soaked in $10 \%$ $\mathrm{HCl}$ for $10 \mathrm{~min}$. They were then stained in acidic glycerol containing $0.05 \%$ fuschin for $15 \mathrm{~min}$ at $75^{\circ} \mathrm{C}$. Acidic glycerol was used for destaining. The degree of mycorrhizal infection in roots was assessed by spreading the root sample evenly in a Petri dish, where a grid $(0.4 \mathrm{~cm}$ side squares) had been previously marked. The Petri dish was observed under the dissecting microscope at a low magnification. First the number of intersects of the root with the grid, and then the intersects of infected roots with the grid were counted. The percentage of infection in the root was calculated by the ratio between the number of intersects with infection and the total number of intersects. Each Petri dish was observed 5 times, and the average taken as the degree of root infection.

Nitrate and ammonium uptake

Nitrogen uptake through defined root regions was studied with roots of carob seedlings grown as described above. All the experiments were performed between 1000 and 1400 hours in order to avoid errors due to diurnal variations. The roots were rinsed in water and root segments of the same colour (white, yellow and brown) obtained from five different plants were cut into pieces of $1 \mathrm{~cm}$ and mixed. Samples of segments $(0.3-1 \mathrm{~g})$ were weighed and transferred to Petri dishes containing $10 \mathrm{ml}$ of $25 \%$ modified Crone solution (Lazof et al. 1992; Cruz et al. 1995; Gessler et al. 1998). The media were gently aerated to maintain adequate oxygen supply and minimise boundary layers around the root segments. Three Petri dishes with root medium but without root segments were used to calculate the loss of nitrate and ammonium not due to absorption by roots. Twenty Petri dishes were prepared for each group of root sections. Every $30 \mathrm{~min}$, during $2 \mathrm{~h}$, five Petri dishes were collected, and solution volumes and nitrogen concentrations of the medium were determined. The values reported are the means of the results obtained.

Determinations of net uptake rates of nitrate and ammonium were based on nitrogen disappearance from the solution per unit time. The rates were expressed as $\mu \mathrm{mol} \mathrm{g}^{-1}$ root fresh weight $\mathrm{h}^{-1}$ and calculated from the changes in nitrogen concentration and solution volumes at consecutive sampling times. 
Nitrate was determined after reduction to nitrite (McNamara et al. 1971), nitrite according to Snell and Snell (1949) and ammonium by the indophenol-blue reaction (Solozano 1969).

\section{Root morphology}

Cleaned root systems were arranged to minimise overlaps in an A3sized perspex tray and scanned in both grayscale [transparency adapter, $150 \mathrm{dpi}$, tagged image file (TIF) format] and colour (reflective, blue background, $96 \mathrm{dpi}$, TIF format). Where necessary, root systems were physically dissected into up to four parts and the images rejoined, before analysis with image analysis software (WinRhizo; Regent Instruments, Quebec). Grayscale images were used to measure total length, link length and topology of the root systems. The root was considered, according to Fitter et al. (1988), as a set of links. Links or internodes were defined as linear portions between a terminal meristem and a branching point (external link) or between two branching points (internal link). Two types of internal links were considered, internal links adjacent to external links were referred to as external-internal; and those without connection to a link with a meristem were referred to as internalinternal links. Root topology was characterised by the magnitude (number of external links) and by altitude ( $a$; the number of links in the longest path between an external link and the base link). The topological indices used, calculated according to Werner and Smart (1973), were the ratio of $a$ to the expected $a[\mathrm{E}(a)]$, i.e. $[a / \mathrm{E}(a)]$ and the ratio of pathlength $(\mathrm{Pe})$ to the expected $\mathrm{Pe}[\mathrm{E}(\mathrm{Pe})]$, i.e. $[\mathrm{Pe} /$ $\mathrm{E}(\mathrm{Pe})]$ (Fitter et al. 1988). At magnitudes $>200$ we used a linear extrapolation of the Werner and Smart data $\{\mathrm{E}(a)=0.299+0.593 \log$ magnitude, $r^{2}=0.999, P<0.001$, and $\log [\mathrm{E}(\mathrm{Pe})]=0.223+1.51 \log$ magnitude, $\left.r^{2}=1.000, P<0.001\right\}$ to calculate expected values, but the relationship is not thought to stray from the linear. The topological indices indicate the degree of branching on a spectrum between the theoretical extremes of dichotomously branched and herringbone structures. Increases in $a / \mathrm{E}(a)$ and $\mathrm{Pe} / \mathrm{E}(\mathrm{Pe})$ indicate more herringbone roots.

The colour images were used to measure the length of white tip and yellow-brown elongation zone in the root systems (hereafter referred to as the lightly pigmented zone). The brown and dark brown parts of the roots were designated as heavily pigmented according to our previous knowledge of carob root morphology (M. A. Martins-Loução, unpublished data). The two root categories were distinguished from the background and the rest of the root system using a colour group selected from a scanned soil colour chart (Munsell 1975): white tips 10YR 7/1-8/4 and elongation zone 10 YR 3/3-8/7.

Data were analysed by two-way ANOVA. Link lengths and topological indices were analysed by analysis of covariance with $\log$ (number of tips) as the covariate, because the indices are scale dependant (Fitter et al. 1988; Green et al. 2003)

\section{Calculations}

Calculation of the potential nitrogen uptake rate of each root section was based on the product of the nitrogen uptake rate per unit weight of the root section and the weight of the root section per root system.

The root to shoot ratio was calculated as the ratio between root dry matter and shoot dry matter.

\section{Results}

Biomass production by carob plants inoculated with AM fungi was greater under low levels of nutrients, i.e. about $30 \%$ dry weight (Fig. 1). Among the other treatments no significant differences were observed with or without mycorrhiza.

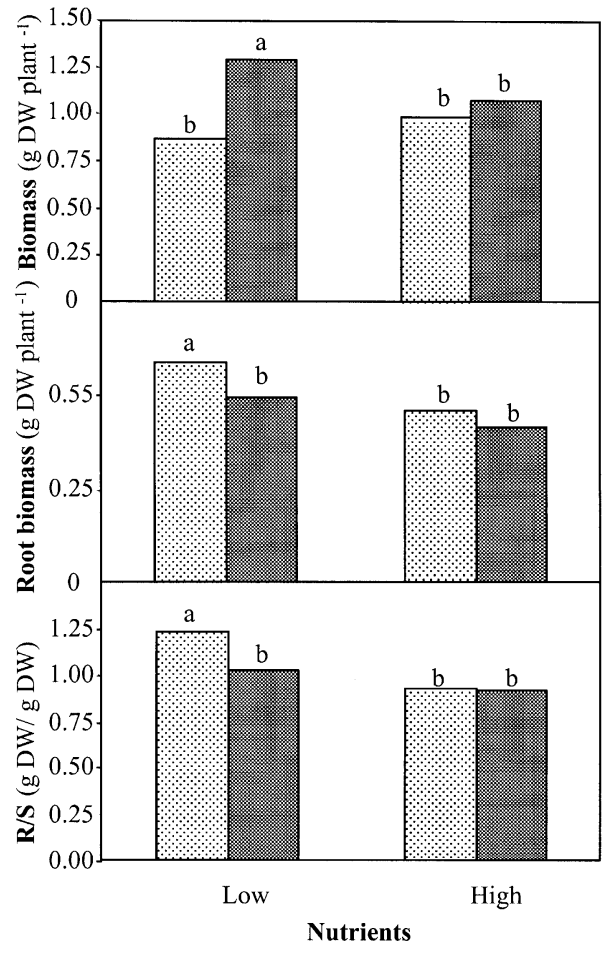

Fig. 1 Plant biomass, root biomass and root to shoot ratio $(R / S)$ of 3-month-old carob seedlings [non-mycorrhizal (grey bars) or mycorrhizal (black bars)] grown with low or high nutrient supply to the root medium. Within panels, values with the same letter are not significantly different according to Fisher's LSD test at $P=0.05$. $D W$ Dry weight

Table 1 Percentage of root infected with arbuscular mycorrhizal (AM) fungi according to treatments: no inoculation and no additional nutrition $(N M L)$; no inoculation and additional nutrition $(N M H)$; mycorrhiza inoculum and no additional nutrition $(M L)$; mycorrhiza inoculum and additional nutrition $(M H)$. Root systems of Ceratonia siliqua grown with AM inoculation and nutrient treatments were divided into three zones according to their colour. Values with the same letter are not significantly different according to Fisher's LSD test at $P=0.05$. Probabilities from the ANOVA are given $(d f=1,20)$

\begin{tabular}{lccl}
\hline \multirow{2}{*}{ Treatment } & \multicolumn{3}{l}{ Root zone (colour) } \\
\cline { 2 - 4 } & White & Yellow & Brown \\
\hline NML & $0.9 \mathrm{c}$ & $0.9 \mathrm{c}$ & $0.4 \mathrm{c}$ \\
NMH & $0.7 \mathrm{c}$ & $0.9 \mathrm{c}$ & $0.3 \mathrm{c}$ \\
ML & $30.0 \mathrm{a}$ & $36.0 \mathrm{a}$ & $5.6 \mathrm{a}$ \\
MH & $12.7 \mathrm{~b}$ & $11.9 \mathrm{~b}$ & $2.8 \mathrm{~b}$ \\
\hline Source & $P$ & $P$ & $P$ \\
\hline AM & 0.010 & 0.059 & 0.001 \\
Nutrients & 0.005 & 0.000 & 0.001 \\
AM $\times$ Nutrients & 0.011 & 0.058 & 0.001 \\
\hline
\end{tabular}

Uninoculated plants developed $<1 \%$ root AM colonisation, higher percentages were observed for the plants exposed to the AM inoculum (Table 1). AM colonisation was higher (30-36\% compared with $11-12 \%)$ for the inoculated plants grown with low than those grown with 
Table 2 Root fresh weight $(\mathrm{g})$ of the three root zones considered (white, yellow and brown) and the respective percentage in relation to the fresh weight of the entire root system of the plant according to treatments. Values with the same letter are not significantly different according to Fisher's LSD test at $P=0.05$. Probabilities from the ANOVA are given below $(d f=1,20)$. For abbreviations, see Fig. 1

Table 3 The total length, white zone, yellow zone and lightly pigmented proportion (white plus yellow zones per unit root length) in root systems of $C$. siliqua according to treatments. Values with the same letter are not significantly different according to Fisher's LSD test at $P=0.05$. Probabilities from the ANOVA are given below $(d f=1,12)$. For abbreviations, see Fig. 1

\begin{tabular}{|c|c|c|c|c|c|c|}
\hline \multirow[t]{2}{*}{ Treatment } & \multicolumn{3}{|c|}{ Root Fresh weight (g) } & \multicolumn{3}{|c|}{ Fresh weight ( $\%$ of total) } \\
\hline & White & Yellow & Brown & White & Yellow & Brown \\
\hline NML & $1.03 \mathrm{~b}$ & $2.77 \mathrm{~b}$ & $2.57 \mathrm{a}$ & 17 & 43 & 40 \\
\hline NMH & $0.15 \mathrm{c}$ & $1.57 \mathrm{c}$ & $1.84 \mathrm{~b}$ & 4 & 44 & 52 \\
\hline ML & $2.06 \mathrm{a}$ & $3.23 \mathrm{a}$ & $2.56 \mathrm{a}$ & 27 & 41 & 32 \\
\hline MH & $0.45 \mathrm{c}$ & $2.00 \mathrm{c}$ & $1.71 \mathrm{~b}$ & 11 & 48 & 41 \\
\hline Source & $P$ & $P$ & $P$ & & & \\
\hline $\mathrm{AM}$ & 0.010 & 0.004 & 0.041 & & & \\
\hline Nutrients & 0.001 & 0.044 & 0.017 & & & \\
\hline AM $\times$ Nutrients & 0.021 & 0.009 & 0.031 & & & \\
\hline
\end{tabular}

\begin{tabular}{lllll}
\hline Treatment & $\begin{array}{l}\text { Length } \\
(\mathrm{cm})\end{array}$ & $\begin{array}{l}\text { White zone } \\
(\mathrm{cm})\end{array}$ & $\begin{array}{l}\text { Yellow zone } \\
(\mathrm{cm})\end{array}$ & $\begin{array}{l}\text { Lightly pigmented } \\
\text { proportion }\end{array}$ \\
\hline NML & 270 & 8.0 & 85 & $0.34 \mathrm{a}$ \\
NMH & 330 & 3.9 & 62 & $0.20 \mathrm{~b}$ \\
ML & 350 & 8.5 & 86 & $0.28 \mathrm{ab}$ \\
MH & 390 & 3.1 & 78 & $0.20 \mathrm{~b}$ \\
\hline Source & $P$ & $P$ & $p$ & $P$ \\
\hline AM & 0.065 & 0.956 & 0.603 & 0.389 \\
Nutrients & 0.136 & 0.058 & 0.344 & 0.011 \\
AM $\times$ Nutrients & 0.790 & 0.774 & 0.629 & 0.389 \\
\hline
\end{tabular}

high levels of nutrients (Table 1). Most of the AM colonisation was observed in the lightly pigmented (white and yellow) parts of the root.

Dry weight root to shoot ratios were significantly higher for non-mycorrhizal plants at a low nutrient level (Fig. 1). No significant differences in root to shoot ratio were observed among plants from the other treatments (NMH, ML or MH).

Nevertheless, roots of the four treatments were quite different. Roots of the treatments without the nutrient supplement (NML and ML) appeared to be more brittle than those of the treatments receiving more nutrients (NMH and $\mathrm{MH}$ ). This was partly due to a higher allocation of biomass to lightly pigmented root regions (Table 2). In NML and ML treatments, the weight of the lightly pigmented root regions (white and yellow parts of the root) represented $60 \%$ and $68 \%$ of the total fresh weight of the root, while for the NMH and $\mathrm{MH}$ treatments the same root fraction corresponded to $48 \%$ and $59 \%$, respectively. The greater proportion of lightly pigmented root regions (white tips and yellow zone) in root systems under low nutrient levels was confirmed on a root length basis (Table 3 ).

Nitrate and ammonium uptake capacities of excised roots, on a fresh weight basis, were higher for the white part of the roots, in contrast to the very limited uptake by the brown parts of the root (Fig. 2). The effects of increased levels of nutrients and mycorrhiza infection on nitrate and ammonium uptake capacity were very similar. Roots grown with high levels of nutrients had lower unit nutrient uptake capacities. AM colonisation also increased potential nitrate uptake rates per unit of biomass of the yellow root parts (Fig. 2), where colonisation was

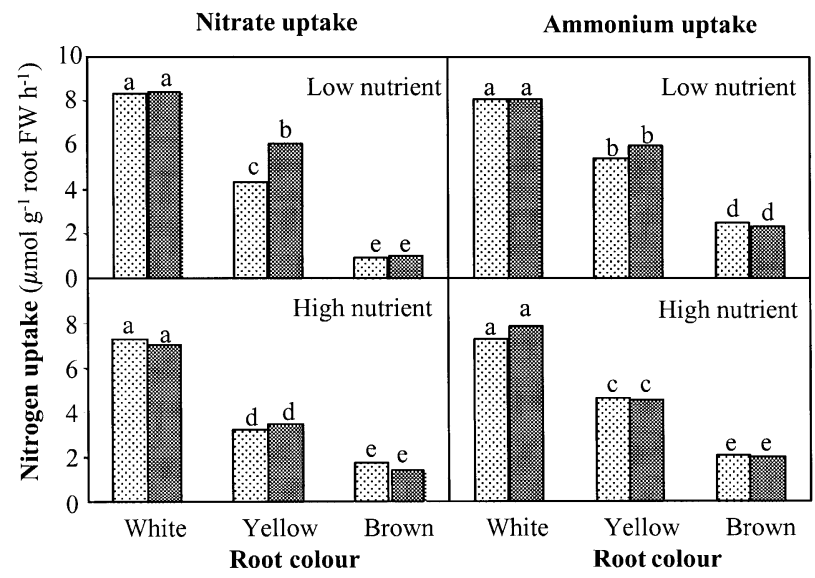

Fig. 2 Nitrate and ammonium uptake rates, on a root fresh weight $(F W)$ basis, according to root pigmentation (white, yellow and brown) and treatment. Carob seedlings [non-mycorrhizal (grey bars) or mycorrhizal (black bars)] were grown for 3 months with low or high nutrient supply to the root medium. Values of nitrate (low and high nutrient) or ammonium (low and high nutrient) uptake rates with the same letter are not significantly different according to Fisher's LSD test at $P=0.05$

more intense (Table 2). The result was that the uptake capacity of the yellow parts of the roots of plants grown under low nutrient supply and infected by AM became similar to that of the white parts of the root (Fig. 3). Neither mycorrhiza nor the nutrient level had a significant effect on unit inorganic nitrogen uptake by the heavily pigmented parts of the roots (Fig. 2).

At low nutrient levels the main effect of the mycorrhiza was to increase the nitrogen uptake capacity of the 


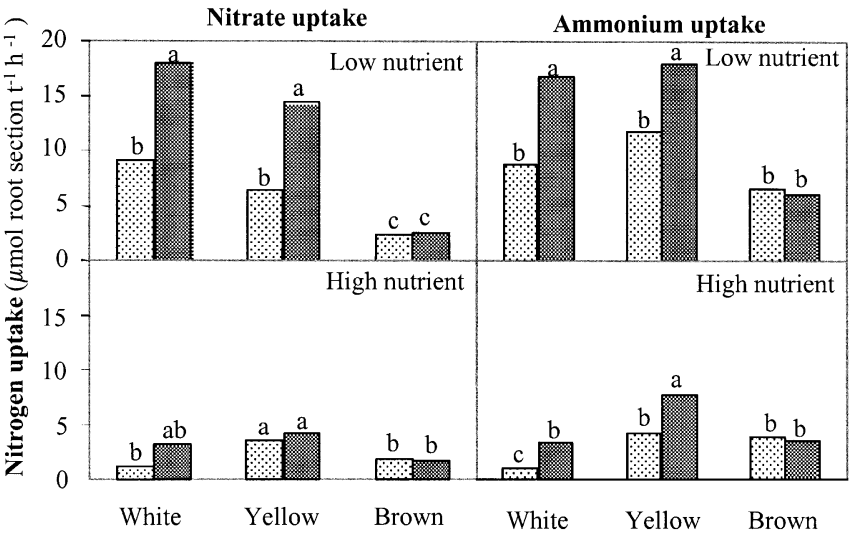

Fig. 3 Nitrate and ammonium uptake per plant, on a root pigmentation basis, according to the root colour (white, yellow and brown) and treatment. Carob seedlings [non-mycorrhizal (grey bars) or mycorrhizal (black bars)] were grown for 3 months with low or high nutrient supply to the root medium. Values of nitrate (low and high nutrient) or ammonium (low and high nutrient) uptake rates with the same letter are not significantly according to Fisher's LSD test at $P=0.05$

Table 4 The topology $[a / E(a)$, where $a$ is the number of links in the longest path between an external link and the base link, and $\mathrm{E}$ $(a)$ is the expected $a$; and $P e / E(P e)$, where Pe is the pathlength and $\mathrm{E}(\mathrm{Pe})$ the expected $\mathrm{Pe}]$ and link lengths [external-external $(E E)$, external-internal $(E I)$, internal-internal $(I I) ; \mathrm{mm}]$ of $C$. siliqua according to treatments. Values are adjusted for the covariate $\log$ (number of tips). Values with the same letter are not significantly different according to Fisher's LSD test at $P=0.05$. $F$-values and associated probabilities from the analysis of covariance are given below $(d f=1,11)$. For other abbreviations, see Fig. 1

\begin{tabular}{llllll}
\hline Treatment & $\mathrm{a} / \mathrm{E}(\mathrm{a})$ & $\mathrm{Pe} / \mathrm{E}(\mathrm{Pe})$ & $\mathrm{EE}$ & $\mathrm{EI}$ & $\mathrm{II}$ \\
\hline $\mathrm{CL}$ & $1.80 \mathrm{ab}$ & 1.46 & 1.04 & 1.01 & $0.75 \mathrm{a}$ \\
$\mathrm{CH}$ & $1.55 \mathrm{ab}$ & 1.09 & 1.44 & 1.22 & $0.90 \mathrm{ab}$ \\
$\mathrm{ML}$ & $2.14 \mathrm{a}$ & 1.79 & 1.31 & 1.18 & $0.80 \mathrm{ab}$ \\
$\mathrm{MH}$ & $1.14 \mathrm{~b}$ & 0.79 & 1.16 & 1.20 & $1.08 \mathrm{~b}$ \\
\hline Source & $P$ & $P$ & $P$ & $P$ & $P$ \\
\hline AM & 0.955 & 0.945 & 0.935 & 0.621 & 0.297 \\
Nutrients & 0.029 & 0.053 & 0.612 & 0.484 & 0.047 \\
AM $\times$ Nutrients & 0.166 & 0.343 & 0.269 & 0.584 & 0.502 \\
\hline
\end{tabular}

younger parts of the root (white and yellow sections, Fig. 3). Increasing the nutrient level of the root medium lead to a reduction in the capacity of roots to take up inorganic nitrogen, in the presence and absence of mycorrhiza (Figs. 3, 4). Plant roots grown in low nutrient levels and with AM colonisation were those with the highest capacity for capturing inorganic nitrogen. These results were confirmed by the plant content of nitrogen, which was also higher for AM plants grown under a low level of nutrients (Fig. 5).

The results suggested that being grown with high nutrient levels negated the effects of AM infection, as far as nitrogen uptake is concerned (Figs. 3, 4, 5). AM infection improved phosphorus uptake by the plants at low and high levels of nutrients, but this was more

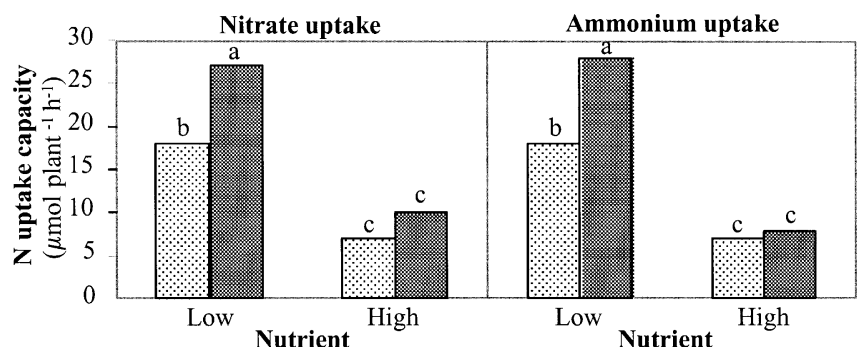

Fig. 4 Nitrate and ammonium uptake rates by the root system, according to the nutrient level in the root medium. Carob seedlings [non-mycorrhizal (grey bars) or mycorrhizal (black bars)] were grown for 3 months with low or high nutrient supply to the root medium. Within panels, values with the same letter are not significantly different according to Fisher's LSD test at $P=0.05$

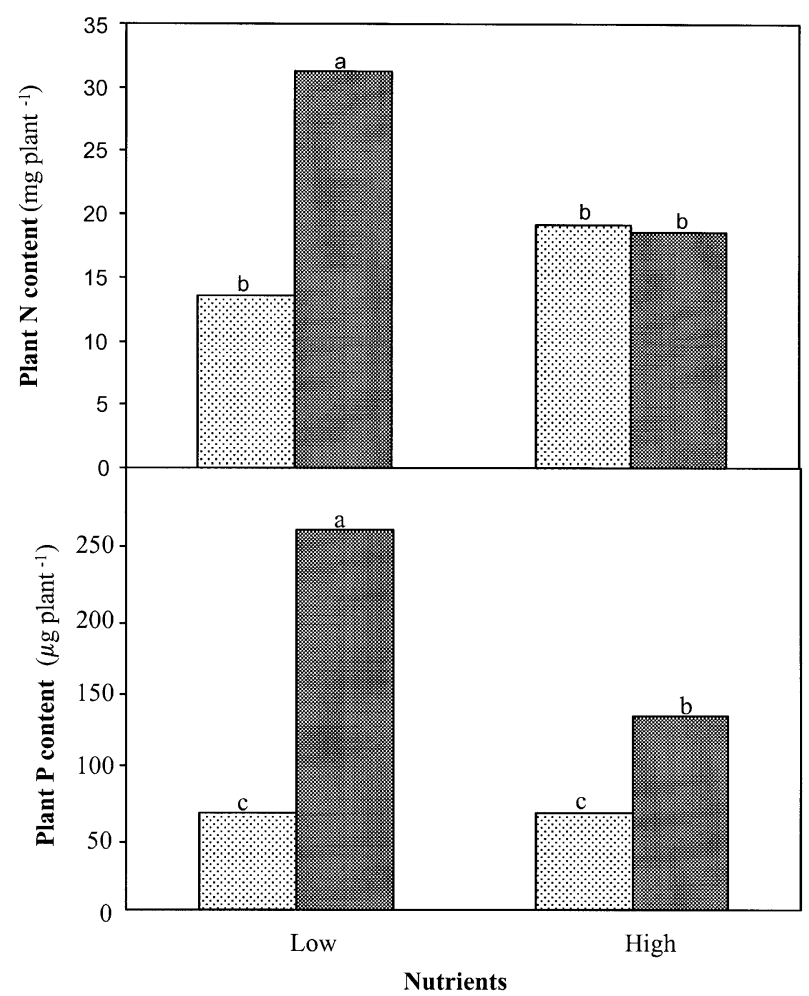

Fig. 5 Plant nitrogen $(N)$ and phosphorus $(\mathrm{P})$ content according to the nutrient level in the root medium. Carob seedlings [nonmycorrhizal (grey bars) or mycorrhizal (black bars)] were grown for 3 months with low or high nutrient supply to the root medium. Within panels, values with the same letter are not significantly different according to Fisher's LSD test at $P=0.05$

noticeable at low levels of nutrients (Fig. 5). It has to be noted, however, that the degree of colonisation by AM fungi was lower under high levels of nutrients (Table 1), perhaps explaining the lower phosphorus content of AM plants grown at high nutrient levels.

AM inoculation did not significantly influence the total root length (Table 3), the length of links, or the degree of branching in carob root systems. There was no significant interaction between AM inoculation and nutrients in these variables (Table 4). The nutrient treatment did not affect 
the total length of root systems, but did influence the arrangement of links within the root systems. High nutrient supply in combination with AM inoculation resulted in more branched (more dichotomous) root systems with longer internal links (Table 4). Root systems with longer internal links tended to have a greater proportion of internal ("old") root length compared with absorbing length (white and yellow zones). This fits the pattern revealed by the colour analysis (Table 3 ) and fresh weight data (Table 2).

\section{Discussion}

The total biomass accumulation, per plant, is comparable to that obtained in previous experiments (Cruz et al. 1993a, 1993b). This study revealed the improved performance of mycorrhizal plants exposed to low levels of nutrients in comparison with those which received supplementary nutrients. This is in agreement with the inhibition of AM formation in the presence of a high concentration of nutrients, especially phosphorus (Peng et al. 1993; Smith and Smith 1996; Graham et al. 1997).

Carob plants were not able to take advantage of high nutrient levels in the root medium, since the growth of plants without AM colonisation was independent of the nutrient levels tested. Besides promotion of plant growth, many other effects have been attributed to AM, including: changes in the root to shoot ratio, increased leaf area, decrease in specific leaf weight, decrease in root longevity, increase or decrease in root branching depending on plant species, and improvement in plant water relations (Auge 2001; Majdi et al. 2001).

Control plants presented root to shoot ratios of about 1.2 , a common value among seedlings of woody plants (Martins-Loução et al. 1996). The possession of a large root system may be advantageous for the sclerophyllous, evergreen trees and shrubs which often dominate the vegetation of Mediterranean-type ecosystems. Nevertheless AM association may increase nutrient acquisition allowing a relatively smaller biomass allocation to the roots in order to optimise plant growth (Lambers et al. 1995).

Special attention was paid to differentiating roots based on their pigmentation, to identify possible relations between pigmentation and root physiological activity. Browning (increase in root pigmentation) is concurrent with but not caused by suberisation, a process that might reduce the absorption efficiency of the roots (López et al. 2001). Our results are is agreement with those of Comas et al. (2000), who found that the onset of browning generally indicated death of the roots as a "functional organ".

Carob plants grown with low levels of nutrients maintained more of their root biomass in the lightly pigmented portions. This was shown by both the colour analysis of root length and by the fresh weight of roots manually dissected by colour. This root architecture would seem to be advantageous for maintaining a high nutrient uptake capacity in conditions of low resource availability. The greater proportion of lightly pigmented roots was achieved, in part, by the lower internal (heavily pigmented) link length under low nutrients, with or without the AM association. Root systems were also more herringbone under low nutrients. In herringbone systems there are a slightly greater number of internal links for a system of given magnitude (Fitter 1991). For example, a purely herringbone system with eight external links (magnitude $=8$ ) has seven internal links, while a purely dichotomous system of the same magnitude has six internal links. Thus, if all links were the same length, it would be expected that the herringbone system would have a greater proportion of internal, or heavily pigmented, root length. However, the difference in the internal number of links in dichotomous and herringbone systems is small in comparison with the influence of internal link length. This suggests that the higher proportion of lightly pigmented root under low nutrients is related to the shorter length of the internal links and not changes in the topological index.

Root systems were more dichotomous under high nutrient conditions, in agreement with the majority of the literature, due to greater local proliferation under high nutrients. AM association has been shown to induce modifications in root system architecture and in root morphogenesis (Berta et al. 1990; Schellenbaum et al. 1991; Bouma et al. 2001). The effects seem to be dependent on fungus and plant species, as well as on environmental conditions (Smith and Read 1997; Bouma et al. 2001; Gao et al. 2001). Root architecture of carob seedlings seemed to be more responsive to nutrient levels than to $\mathrm{AM}$ association.

The importance of AM in nitrogen uptake and metabolism is still controversial. It seems that the external mycelium of AM fungi can take up organic as well as inorganic nitrogen, and that it shows a preference for ammonium as the inorganic nitrogen source (Whipps 2001). Much less is known about AM (fungi plus plant) uptake rates and preferences (Smith and Read 1997).

Nitrate and ammonium uptake capacities decrease from the apex to the more mature parts of carob roots (Cruz et al. 1995). This gradient was still visible when assessed on the basis of root pigmentation, with higher uptake rates through the white and yellow parts of the root. Roots growing in the presence of low levels of nutrients displayed higher nitrogen uptake capacities on a root weight basis, in agreement with the majority of studies (Bloom et al. 1993; Crawford 1995). This is due to an increase in the number of transporters per unit root area in the presence of low concentrations of nutrients (Bloom et al. 1993; George et al. 1995). The higher nitrate uptake rates observed for the elongation and younger zone (yellow parts of the root) of the mycorrhizal plants grown with low levels of nutrients may be due to the presence of the fungi, since these areas have the highest rates of AM colonisation.

For control and AM plants grown under low nutrient availability, the elongation zone is that which contributes 
most to nitrate and ammonium uptake. It is also clear that the presence of high levels of nutrients results in a decrease in nitrate and ammonium uptake potential, due to both a decrease in the nitrogen uptake capacity per root length and a reduction of the areas that contribute most to nutrient uptake. These calculations are in agreement with the total nitrogen content of the plant, which was also much more improved by AM association in the presence of low nutrient levels. Several works have shown that mycorrhizal fungi are involved in the uptake and transfer of inorganic nitrogen (Smith and Read 1997). The significance of that contribution to plant nutrition is more controversial. Most attention has been focused on the ability of arbuscular mycorrhizae to increase plant growth by enhancing phosphorus uptake (Gange 2000), relieving the plant from phosphorus stress (Fitter and Hay 2002). AM association increased the nitrogen content of carob grown under low nutrient levels by approximately 100\%, and biomass accumulation by $30 \%$, showing that the arbuscular mycorrhiza was important for the nitrogen nutrition of the plant. Considering that the increment in the phosphorus content of AM plants gown at high levels of nutrients was not translated into an increment of plant biomass accumulation or nitrogen content, the increment in nitrogen content and biomass of AM plants grown at low levels of nutrients cannot be exclusively attributed to a better phosphorus status of the plants. Therefore, it seems that nitrogen and phosphorus acquisition are influenced by AM association in different ways.

We conclude that nutrient availability had a much stronger effect on root architecture than the arbuscular mycorrhiza, and that the latter increased nitrogen uptake capacity and plant nitrogen content under low levels of nutrients. The results suggest that in low-resource environments, root system physiology adapts to maximise uptake capacity, and root system morphology adapts to maximise active uptake length. The role of the arbuscular mycorrhiza was to increase the uptake capacity of the active zone. AM colonisation was higher in low-resource environments; this tendency appears to have additional growth benefits to the carob plants unrelated to nutritional aspects. This study is a first step in relating root architecture and mycorrhizal colonisation to the functional aspects of nutrient acquisition.

Acknowledgements The Anglo-Portuguese Joint Research Programme-Treaty of Windsor Programme celebrated between the British Council and Conselho de Reitores das Universidades Portuguesas-supported this work. The Scottish Agricultural College receives financial support from the Scottish Executive Environment and Rural Affairs Department.

\section{References}

Auge RM (2001) Water relations, drought and vesicular-arbuscular mycorrhizal symbiosis. Mycorrhiza 11:3-42

Barker SJ, Tagu D, Delp G (1998) Regulation of root and fungal morphogenesis in mycorrhizal symbioses. Plant Physiol 116:1201-1207
Berta G, Fusconi A, Trotta A, Scannerini S (1990) Morphogenetic modifications induced by the mycorrhizal fungus Glomus strain E3 in the root system of Allium porrum L. New Phytol 114:207-215

Bloom AJ, Jackson LE, Smart DR (1993) Root growth as a function of nitrate and ammonium in the root zone. Plant Cell Environ 16199-206

Bouma TJ, Yanai RD, Elkin AD, Hartmond U, Flores-Alva DE, Eissenstat DM (2001) Estimating age-dependent costs and benefits of roots with contrasting life span: comparing apples and oranges. New Phytol 150:685-695

Brundrett M (1996) Working with mycorrhizas in forestry and agriculture Gamberra: Australia. Australian Centre for International Agricultural Research

Comas LH, Eissenstat DM, Lakso AN (2000) Assessing root death and root system dynamics in a study of grape canopy pruning. New Phytol 147:171-178

Correia P, Martins-Loução MA (1997) Leaf nutrient variations in fertigated mature carob trees ( Ceratonia siliqua L). Tree Physiol 17:813-819

Crawford, NM (1995) Nitrate: nutrient and signal for plant growth. Plant Cell 7:859-868

Cruz C, Lips SH, Martins-Loução MA (1993a)Growth and nutrition of carob plants as affected by nitrogen sources. J Plant Nutr $16: 1-15$

Cruz C, Lips SH, Martins-Loução MA (1993b) Effect of root temperature on carob growth: nitrate versus ammonium nutrition. J Plant Nutr 16:1517-1530

Cruz C, Lips SH, Martins-Loução MA (1995) Uptake regions of inorganic nitrogen in roots of carob seedlings. Physiol Plant 95:167-175

Cruz, C, Lips, SH, Martins-Loução, MA (1997) Changes in the morphology of roots and leaves of carob seedlings induced by nitrogen source and atmospheric carbon dioxide. Ann Bot 80:817-823

Fitter AH (1986) The topology and geometry of plant root systems: influence of watering rate on root system topology in Trifolium pratense. Ann Bot 58:91-101

Fitter AH (1991) The ecological significance of root system architecture: an economic approach. In: Atkinson D (ed) Plant root growth: an ecological perspective. Blackwell, Oxford

Fitter, AH, Hay, RKM (2002) Environmental physiology of plants, 2nd edn. Academic Press, London

Fitter AH, Nichols R, Harvey ML (1988) Root system architecture in relation to life history and nutrient supply. Funct Ecol 2:345351

Gange A (2000) Arbuscular mycorrhizal fungi, collembola and plant growth. Trends Ecol Evol 15:369-375

Gao L-L, Delp G, Smith SE (2001) Colonization patterns in a mycorrhiza-defective mutant tomato vary with different arbuscular-mycorrhizal fungi. New Phytol 151:477-491

George E, Marschner H, Jakobsen I (1995) Role of arbuscular mycorrhizal fungi in uptake of phosphorus and nitrogen from soil. Crit Rev Biotechnol 15:257-270

Gessler A, Schneider S, Sengbusch D, Weber P, Hanemann U, Huber C, Rothe A, Kreutzer K, Rennenberg H (1998) Field and laboratory experiments on net uptake of nitrate and ammonium by the roots of spruce ( Picea abies) and beech (Fagus sylvatica) trees. New Phytol 138:275-285

Graham, JH, Duncan, LW, Eissenstat, DM (1997) Carbohydrate allocation patterns in citrus genotypes as affected by phosphorus nutrition, mycorrhizal colonisation and mycorrhizal dependency. New Phytol 135:335-343

Green JJ, Baddeley JA, Watson CA (2003) Root development and field survival in a Mediterranean shrub: Pistacia lentiscus. Ann Bot (in press)

Hewitt EJ (1966) Sand and water culture methods used in the study of plant nutrition. Technical communication no. 22. Commonwealth Agricultural Bureaux. Eastern Press, London

Lambers, H, Atkin, OK, Scheurwater, I (1995) Respiratory patterns in roots in relation to their functioning. In: Waisel Y, Eschel A, 
Kafkafi K (eds) Plant roots The hidden half. Dekker, New York, pp 229-263

Lazof DB, Rufty TW, Redinbaugh MG (1992) Localization of nitrate absorption and translocation within morphological regions of corn root. Plant Physiol 100:1251-1258

López B, Sabaté S, Gracia CA (2001) Fine-root longevity of Quercus ilex. New Phytol 151:437-441

Lynch J(1995) Root architecture and plant productivity. Plant Physiol 109:7-13

Majdi H, Damm E, Nylund J-E (2001) Longevity of mycorrhizal roots depends on branching order and nutrient availability. New Phytol 150:195-202

Martins-Loução MA, Brito de Carvalho JB (1990) A cultura da Alfarrobeira. Série de Divulgação no. 1. DGAP, Lisboa

Martins-Loução MA, Duarte PJ, Cruz C (1996) Phenological and physiological studies during carob ( Ceratonia siliqua $\mathrm{L}$ ) seed germination. Seed Sci Technol 24:33-47

McNamara AL, Meeker GB, Shaw PD, Hageman RH (1971) Use of a dissimilatory nitrate reductase from Escherichia coli and formate as a reductive system for nitrate. J Agric Food Chem 19:229-231

Munsell (1975) Soil colour chart. Munsell Colour, Baltimore, Md.

Peng S, Eissenstat DM, Graham JH, Williams K, Hodge NC (1993) Growth depression of mycorrhizal citrus at high phosphorus supply: analysis of carbon costs. Plant Physiol 101:1063-1071

Schellenbaum L, Berta G, Ravolanirina F, Tisserant B, Gianinazzi S, Fitter AH (1991) Influence of endomycorrhiza infection on root morphology in a micropropagated woody plant species (Vitis vinifera L). Ann Bot 68:135-141

Smilauerova M, Smilauer P (2002) Morphological responses of plant roots to heterogeneity of soil resources. New Phytol 154:703-715

Smith SE, Read DJ (1997) Mycorrhizal symbiosis, 2nd edn. Academic Press, London

Smith FA, Smith SE (1996) Mutualism and parasitism: diversity, function and structure in the "arbuscular" VA mycorrhizal symbiosis. Adv Bot Res 22:1-43

Snell FD, Snell CT (1949) Colorimetric methods of analysis. Van Nostrand, New York

Solozano L (1969) Determination of ammonium in natural waters by the phenolhypochlorite method. Limnol Oceanogr 14:799_ 801

Tisserant B, Schellenbaum L, Gianinazzi V, Gianinazzi S, Berta G (1992) Influence of infection by an endomycorrhizal fungus on root development and architecture in Platanus acerifolia. Allionia 30:171-181

Wantanabe FS, Olsen SR (1965) Test of an ascorbic acid method for determining phosphorus in water and $\mathrm{NaHCO}_{3}$ extracts from soil. Soil Sci Soc Proc 29:677-678

Werner C, Smart JS (1973) Some new methods of topologic classification of channel networks. Geogr Anal 5:271-295

Whipps JM (2001) Microbial interactions and biocontrol in the rhizosphere. J Exp Bot 52:487-511 